\title{
O MODELO ONDULATÓRIO COMO ESTRATÉGIA DE PROMOÇÃO DA EVOLUÇÃO CONCEITUAL EM TÓPICOS SOBRE A LUZ EM NÍVEL MÉDIO
}

\section{The wave model as a strategy for promoting conceptual change in topics on the light at High School}

\author{
Jales de Aquino Silva ${ }^{1}$. Célia Maria Soares Gomes de Sousa ${ }^{2}$
}

\begin{abstract}
Resumo: Este estudo trata da verificação da viabilidade de se promoverem estratégias de ensino de tópicos sobre a luz a partir da sua natureza ondulatória, buscando evidências de aprendizagem em um curso de nível Médio. Um grupo de alunos foi submetido a situações instrucionais, elaboradas na perspectiva da Teoria dos Campos Conceituais de Vergnaud e da Teoria da Aprendizagem Significativa de Ausubel, com o objetivo de criar condições favoráveis à evolução conceitual e, com isso, promover uma maior compreensão, por parte dos alunos, dos fenômenos relacionados ao tema. Apesar das condições de infraestrutura precárias para a realização deste estudo, os resultados nos revelaram evidências de evolução conceitual e a viabilidade de se tratarem tópicos sobre a luz a partir da teoria ondulatória.
\end{abstract}

Palavras-chave: Ensino de física. Ensino Médio. Aprendizagem significativa. Teoria dos Campos Conceituais de Vergnaud.

\begin{abstract}
This study deals with the verification of the viability of strategies for teaching topics on light from its wave nature, by searching for evidence of learning in a high school course. A group of students was submitted to situations developed from the perspective of the Vergnaud's Theory of Conceptual Fields and the Theory of Meaningful Learning, by Ausubel, with the objective of creating favorable conditions for conceptual development, and, by doing so, to promote greater understanding by the students of the phenomena related to the topic. Despite the poor infra-structure conditions for the development of the study, the results showed evidence of conceptual development and the viability of dealing with light-related topics from the perspective of wave theory.
\end{abstract}

Keywords: Physics teaching. High school. Theory of meaningful learning. Vergnaud's Theory of Conceptual Fields.

\footnotetext{
${ }^{1}$ Secretaria de Educação do Distrito Federal, Centro Educacional 06 de Taguatinga. QNL 01, Área Especial 01, CEP 72.150-508, Taguatinga, Brasília, DF, Brasil. E-mail: <jalesdeaquino@gmail.com>

${ }^{2}$ Universidade de Brasília (UnB), Instituto de Física, Brasília, DF, Brasil.
} 
Silva, J. A.; Sousa, C. M. S. G.

\section{Introdução}

Duas questões motivaram a realização deste estudo. Uma delas refere-se a como poderíamos entender melhor os processos pelos quais o sujeito aprende e, com isso, possibilitar uma maior compreensão dos conceitos físicos que tentamos ensinar a eles em situações de sala de aula. A outra questão trata de procurar verificar uma suposição de um dos autores deste trabalho, baseado na prática docente, sobre se o ensino de Óptica, baseado em aspectos relacionados à natureza da luz, favoreceria a aprendizagem desse conteúdo em nível médio.

Quando trabalhamos Óptica no Ensino Médio, frequentemente, damos muita atenção ao modelo de raio de luz, consumindo boa parte do tempo traçando segmentos de retas para explicarmos a formação de imagens por reflexão e por refração. Ficamos muito tempo trabalhando a Óptica Geométrica restando pouco ou nenhum tempo para a Óptica Ondulatória. Para Gircoreano e Pacca (2001), essa maneira usual de estudar Óptica não deixa evidente que a luz se propaga num espaço tridimensional, que há uma fonte de luz e que existem obstáculos para a propagação; os aspectos concernentes à natureza da luz são, em geral, desconsiderados. Para Paulo, Paulo e Rinaldi (1997), deve-se dar menor ênfase ao ensino de Óptica Geométrica no Ensino Médio, em favor de uma maior ênfase à discussão sobre a natureza da luz, por ser mais importante para a formação profissional, científica e cultural do indivíduo entender a natureza da luz do que lidar com lentes e prismas.

Como base teórica, utilizamos a Teoria dos Campos Conceituais de Vergnaud. Segundo Moreira (2002), essa teoria está sendo utilizada no estudo sobre aprendizagem dos conceitos físicos, e tem se mostrado útil na melhoria da aprendizagem, na identificação de dificuldades de aprendizagem de tais conceitos e na seleção de situações instrucionais que possam ajudar na progressiva superação dessas dificuldades. Quanto à importância do conhecimento prévio para a elaboração das situações que trabalhamos com os estudantes, recorremos à proposta de Ausubel, na Teoria da Aprendizagem Significativa. Com isso, acreditamos que essas duas teorias nos fornecem elementos suficientes para entendermos melhor como se dá o processo de aprendizagem e para elaboração de situações instrucionais mais favoráveis.

A partir desses questionamentos e dos referenciais teóricos escolhidos, nosso estudo focou a verificação da viabilidade de se construírem estratégias de ensino de tópicos sobre a luz a partir da sua natureza ondulatória, buscando evidências de aprendizagem de alunos em um curso de nível Médio. Esse estudo foi desenvolvido em uma escola da rede pública de ensino do Distrito Federal, durante o primeiro semestre de 2008, com alunos da disciplina Física 2 da Educação de Jovens e Adultos, $3^{\circ}$ segmento (equivalente ao Ensino Médio do curso regular).

\section{Referencial teórico}

Segundo Vergnaud (2007), o conhecimento se encontra organizado em campos conceituais, dos quais o sujeito se apropria ao longo do tempo, através de experiência, maturidade e aprendizagem. Campos conceituais podem ser definidos como grandes conjuntos, informais e heterogêneos, de situações-problema cuja análise e tratamento requerem diversas classes de conceitos, procedimentos e representações simbólicas que se conectam umas com as outras. 
A Teoria dos Campos Conceituais parte do pressuposto de que a essência do desenvolvimento cognitivo é a conceitualização. Isso porque Vergnaud considera que o fator essencial da dificuldade dos estudantes com a resolução de problemas de Matemática, que Greca e Moreira (2002) estendem para problemas em Física, é a dificuldade do sujeito em relacionar convenientemente os conceitos pertinentes à situação proposta.

Para Vergnaud (2007), o ensino deve facilitar a construção de conhecimentos explícitos e cientificamente aceitos, a partir do conhecimento implícito; se o aprendiz consegue incorporar, na sua estrutura cognitiva, conhecimentos cientificamente aceitos, dizemos que houve evolução conceitual. O momento ideal para se promover evolução conceitual é aquele no qual o sujeito se confronta com situações, porque os conceitos só se tornam significativos através delas; uma situação é entendida como uma tarefa a ser cumprida. Segundo Sousa e Fávero (2002), a teoria dos campos conceituais parte do princípio de que a obtenção do conhecimento está determinada pelas situações abordadas pelo sujeito e pelas ações que ele executa durante sua resolução. Para Andrés e Pesa (2004), a potencialidade dessa teoria está na possibilidade de se compreenderem os processos que subjazem à cognição, em particular, a construção de representações internas do sujeito.

Segundo Moreira (2002), Vergnaud (2007) define conceito como sendo composto de três conjuntos:

- S (o referente): é um conjunto de situações que dão sentido ao conceito;

- I (o significado): é um conjunto de invariantes (objetos, propriedades e relações) sobre os quais repousa a operacionalidade do conceito, também denominado invariantes operatórios associados ao conceito, ou o conjunto de invariantes que podem ser reconhecidos e usados pelos sujeitos para analisar e dominar as situações do primeiro conjunto;

- R (o significante): é um conjunto de representações simbólicas (linguagem natural, gráficos e diagramas, sentenças formais etc.) que podem ser usadas para indicar e representar esses invariantes e, consequentemente, representar as situações e os procedimentos para lidar com elas.

O sentido de um conceito está na relação do sujeito com as situações e os significantes. Precisamente, são os esquemas que constituem o sentido dessa situação ou desse significante para esse sujeito. Vergnaud (2007) chama de esquemas as ações e sua organização invariante evocadas em um sujeito por uma situação ou por um significante. Os esquemas têm como ingredientes os invariantes operatórios, ou seja, os conceitos-em-ação e teoremas-emação, constituindo os conhecimentos contidos nos esquemas.

Teorema-em-ação é uma proposição que pode ser verdadeira ou falsa; conceito-emação é uma categoria de pensamento tida como pertinente. Esse conhecimento é precisamente implícito e o aprendiz tem dificuldade em explicitá-lo porque, geralmente, existe uma lacuna considerável entre os invariantes que o sujeito constrói e os invariantes que constituem o conhecimento científico (MOREIRA, 2002).

Segundo Moreira (1999), a aprendizagem significativa implica relacionar, de forma não arbitrária e substantiva (não literal), uma nova informação a outras com as quais o indivíduo já esteja familiarizado e quando esse indivíduo adota uma estratégia correspondente para assim proceder.

Dessa definição, podemos destacar três itens: 
Silva, J. A.; Sousa, C. M. S. G.

- Não-arbitrariedade: a nova informação não se relaciona com qualquer aspecto preexistente na estrutura cognitiva, mas com conhecimentos especificamente relevantes existentes, que Ausubel denomina subsunçores.

- Substantividade: ao se aprender de forma significativa, retém-se a substância das novas ideias, não as palavras precisas usadas para sua expressão.

- Atitude proativa: $\mathrm{O}$ indivíduo deve estar disposto a conectar de maneira não arbitrária e não literal o novo conhecimento com a sua estrutura cognitiva preexistente.

No tocante à postura do professor na facilitação da aprendizagem significativa, Moreira (1999) aponta quatro tarefas fundamentais:

- Identificar, na matéria de ensino, os conceitos e princípios unificadores, inclusivos, com maior poder explanatório e propriedades integradoras, e organizá-los hierarquicamente de modo que, progressivamente, abranjam os menos inclusivos até chegar aos exemplos e dados específicos.

- Identificar quais os subsunçores (conceitos, proposições, ideias claras, precisas, estáveis) relevantes à aprendizagem do conteúdo a ser ensinado, que o aluno deveria ter em sua estrutura cognitiva para poder aprender significativamente este conteúdo.

- Diagnosticar aquilo que o aluno já sabe; determinar, dentre os subsunçores especificamente relevantes (previamente identificados ao organizar a matéria de ensino), quais os que estão disponíveis na estrutura cognitiva do aluno.

- Auxiliar o aluno a assimilar a estrutura da matéria de ensino e organizar sua própria estrutura cognitiva nessa área de conhecimentos, por meio da aquisição de significados claros, estáveis e transferíveis.

Ao longo do desenvolvimento do trabalho com os alunos, são propostas situações em forma de tarefas, como propõe Vergnaud (2007), inicialmente com intuito de identificar quais conceitos-em-ação e teoremas-em-ação os estudantes apresentam. Esses conhecimentos-em-ação identificados, segundo a teoria de Ausubel, comporão o conhecimento prévio, dentre os quais selecionaremos aqueles relevantes para o processo de conceitualização. Como sugere Moreira (2002), a teoria de Vergnaud pode ser usada para analisar as dificuldades dos estudantes na conceitualização em Ciências em termos de invariantes operatórios, ou seja, em termos de quais os conceitos e teoremas-em-ação que os estudantes estariam usando e de quão distantes estariam dos conceitos e teoremas científicos adequados à resolução do problema em pauta.

\section{Metodologia}

O estudo foi realizado em uma escola que pertence à rede pública de ensino do Distrito Federal, na cidade satélite de Taguatinga, durante o primeiro semestre de 2008, no turno noturno. Os sujeitos do estudo eram alunos da disciplina Física 2 da Educação de Jovens e Adultos (EJA), $3^{\circ}$ segmento (equivalente ao Ensino Médio). O programa dessa disciplina acompanha o da $2^{a}$ série do Ensino Médio, e deve ser cumprido ao longo de um semestre 
com três horas-aula de 40 minutos cada; algumas turmas tinham aulas duplas. Das cinco turmas, em três as aulas foram conduzidas com atividades experimentais interativas, a partir das quais foram propostas questões. A partir das respostas dos alunos, procurávamos: evidências de conceitos e teoremas-em-ação, promover evolução conceitual e verificar, então, se é viável promover o ensino de Óptica a partir da teoria ondulatória.

As turmas A, B e C, com um total de 64 alunos que foram até o final do curso, formaram o grupo de trabalho, sendo que, destes, apenas 16 fizeram todos os testes propostos; nesse grupo foram desenvolvidas as atividades experimentais interativas e as tarefas na forma de questões. As turmas D e E, com 36 alunos que foram até o final, formaram o grupo de comparação, sendo que destes, apenas dez fizeram todos os testes; nesse grupo foram desenvolvidas as mesmas atividades experimentais, mas não as tarefas. Como há um baixo índice de frequência às aulas, poucos participaram de todas as avaliações.

Optamos por utilizar um grupo de trabalho e um de comparação com o objetivo de verificar o impacto dos diferentes tratamentos nesses grupos.

Como a escola não possuía o material necessário para a execução das atividades experimentais, exceto um retroprojetor, utilizamos material de kits para laboratório que já possuíamos; alguns itens não disponíveis foram adquiridos em lojas comerciais.

Nossa hipótese era a de verificar a viabilidade de construir estratégias de ensino de tópicos sobre a luz a partir da sua natureza ondulatória. Optamos, então, por propor as situações a partir de atividades experimentais interativas, através das quais pudéssemos apresentar conceitos e ideias básicas sobre ondas para, daí, concomitantemente, apresentarmos o comportamento ondulatório da luz. Procuramos executar atividades para as quais o modelo ondulatório fosse necessário para fundamentá-las e que podiam ser facilmente reproduzidas. Para isso, o tratamento inclui os fenômenos da reflexão, interferência e difração, produzidos com ondas em molas slinky e na cuba de ondas. Em momentos oportunos, usamos feixes de laser provenientes de uma caneta para reproduzirmos os fenômenos de reflexão, interferência e difração como as ondas na cuba. Optamos por atividades experimentais como ponto de partida porque a nossa experiência indica que esse tipo de atividade motiva os alunos. Optamos, também, por iniciar com ondas formadas em molas e numa cuba com água porque as frentes de ondas seriam facilmente observadas, fornecendo uma estrutura menos abstrata do que aquela das ondas luminosas e ideal para introduzirmos os conceitos básicos sobre ondas.

Iniciamos os trabalhos em sala de aula com a identificação dos conhecimentos prévios. Em um primeiro momento, investigamos o que os alunos sabiam sobre movimento ondulatório. Isso foi feito a partir das respostas às seguintes questões: $\mathrm{O}$ que a palavra movimento lembra? O que é movimento ondulatório? No espaço entre essas perguntas, promovemos uma breve discussão sobre o que foi estudado em Física 1, quando se trabalhou com a cinemática e a dinâmica do ponto material. Em um segundo momento, foi aplicado um pré-teste, através do qual também investigamos a existência de conhecimentos prévios sobre luz.

Nas aulas seguintes, promovemos as atividades, as quais foram separadas em quatro conjuntos:

\section{Conjunto de atividades 1 - Conceitos iniciais sobre ondas}

Discutimos sobre os princípios e conceitos fundamentais sobre ondas. Usamos ondas produzidas em molas slinky e em uma cuba de ondas sobre um retroprojetor. 
Silva, J. A.; Sousa, C. M. S. G.

\section{Conjunto de atividades 2 - Reflexão}

Discutimos o fenômeno da reflexão de ondas e a sua similaridade com a reflexão de feixes de luz. Usamos, mais uma vez, molas slinky para apresentar reflexão de ondas unidimensionais, reflexão de ondas com frentes retas e circulares numa cuba de ondas sobre um retroprojetor e reflexão de feixes laser em espelhos planos e curvos.

\section{Conjunto de atividades 3 - Interferência}

Discutimos o fenômeno da interferência de ondas, usando mais uma vez molas slinky e ondas bidimensionais com frentes circulares produzidas na superfície de certa porção de água na cuba de ondas.

\section{Conjunto de atividades 4 - Difração}

Neste último conjunto de atividades, evidenciamos o caráter ondulatório da luz por meio do fenômeno da difração. Usamos a cuba de ondas e feixes de laser.

Finalizado cada conjunto de atividades, era feita uma breve revisão das mesmas. Em seguida, por meio de aulas expositivas, formalizavam-se os conceitos discutidos. Ao final de todo o tratamento, os alunos responderam a um pós-teste.

Nossa tomada de dados foi guiada com o intuito de averiguar se nosso tratamento promoveu alguma evolução conceitual, ou seja, se os alunos desenvolveram teoremas e conceitos-em-ação cientificamente aceitos. Para termos esses dados registrados, as aulas no grupo de trabalho foram gravadas em áudio nos momentos em que trabalhávamos as atividades experimentais e as situações na forma de perguntas. Além disso, após cada conjunto de atividades, os alunos eram submetidos a um teste avaliativo versando sobre essas situações. Os alunos da turma de comparação foram submetidos aos mesmos testes.

Em nenhum momento, foi dito aos alunos sobre os nossos reais objetivos com as atividades experimentais e com as situações propostas; queríamos que tudo se passasse como uma situação corriqueira de sala de aula. Com isso, não foi revelado os termos pré-teste, pósteste e teste; todos foram chamados de avaliações.

Com os testes, queríamos identificar evidências de evolução conceitual a partir das situações trabalhadas durante as aulas; por isso, as questões foram baseadas nessas situações. Com o pré-teste, queríamos identificar conhecimentos prévios relevantes, para o desenvolvimento das situações propostas. O pós-teste foi elaborado a partir do pré-teste, e incluímos questões gerais sobre as situações tratadas durante as aulas; queríamos avaliar o impacto final do tratamento nos alunos.

A data de aplicação de cada teste era previamente divulgada, e sempre orientávamos os alunos a escreverem o que eles sabiam, usando suas próprias palavras, sem se preocupar com a nota. Todos os testes, com exceção do pré-teste, foram corrigidos e as notas divulgadas; orientávamos aqueles com notas baixas a se esforçarem para obter nota melhor na próxima etapa avaliativa, que já seria considerada como uma recuperação. A duração de cada teste era de duas aulas (oitenta minutos). 


\section{Análise dos dados e discussão}

\section{Identificação dos conhecimentos prévios relevantes}

Partindo do princípio de que os alunos matriculados em Física 2 já haviam tido contato com o conteúdo curricular de Física 1, quando se estudou a cinemática e a dinâmica do ponto material, procuramos, na primeira aula, identificar as ideias gerais que os estudantes apresentavam sobre o assunto estudado em Física 1 e, paulatinamente, introduzir a ideia de movimento ondulatório para, então, avançar para o comportamento ondulatório da luz.

\section{Os corpos se movem! O que a palavra movimento lembra?}

Para efeito de simplificação, foi pedido aos alunos considerarem os corpos como pontos materiais. As respostas eram anotadas no quadro. Tanto no grupo de trabalho como no de comparação, as respostas relevantes se equipararam. As respostas mais frequentes eram aquelas que associavam movimento com deslocamento e aquelas sobre a necessidade de forças para dar início ao movimento; normalmente, usavam a palavra impulso para denominar força. Pouquíssimos alunos citavam a velocidade e aceleração como grandezas pertinentes ao movimento dos corpos, e poucos lembraram que um corpo se move quando sua posição muda em relação a um referencial.

\section{O que é movimento ondulatório?}

Mais uma vez, as respostas se equipararam nos dois grupos. Basicamente, os alunos respondiam a essa questão a partir de exemplos nos quais se observam fenômenos ondulatórios: ondas no mar, o som se propaga na forma de ondas, ondas se propagando em uma corda, terremotos, ondas de estações de rádio.

Percebemos, nessa discussão, que, basicamente, os alunos associavam movimento com força e deslocamento, mas não apresentaram a ideia básica para se produzirem ondas a partir de algo vibrando.

\section{O pré-teste e o pós-teste}

Apenas 16 alunos do grupo de trabalho participaram de todos os testes; somente esses foram considerados para a análise de dados.

As respostas relevantes obtidas no pré-teste confirmaram o que já tínhamos obtido nas discussões da primeira aula. Em geral, os alunos associaram movimento com mudança de posição, perceberam que ele pode ser alterado e quais alterações possíveis. Confirmaram a necessidade de termos algo interagindo com uma corda para termos nela um movimento ondulatório, mas tiveram dificuldades de identificar o caráter oscilatório dessa interação e do movimento ondulatório.

Em algumas questões do pré-teste, tínhamos a intenção de identificar o conhecimento prévio sobre luz. Notamos, na maior parte das respostas, uma forte concepção da luz como energia. Percebemos outra forte concepção: a representação da luz saindo de uma lâmpada com segmentos de retas; mas, em nenhum caso, foi representado o sentido de propagação. Quando perguntados sobre a relação entre ondas e luz, a maioria dos estudantes respondeu 
Silva, J. A.; Sousa, C. M. S. G.

que há alguma relação; as justificativas mais relevantes indicavam que ondas e luz são entes que se espalham quando produzidos e que, por isso, deveria haver alguma relação entre elas.

Notando, então, que, em geral, os estudantes já possuíam a ideia de como produzir um movimento e que já conheciam exemplos de fenômenos ondulatórios, nas aulas seguintes, procuramos ancorar, nessas ideias, a produção de um movimento oscilatório como causa de um movimento ondulatório. Percebendo, também, que as duas concepções básicas sobre a luz eram a energética e a representação geométrica por meio de raios, e que os estudantes já acreditavam haver alguma relação entre ondas e luz, procuramos ancorar, nessas ideias, o comportamento ondulatório da luz como mais uma alternativa.

Comparando as respostas obtidas no pré-teste e no pós-teste, chegamos às seguintes conclusões no pré-teste:

- quatro alunos $(25,00 \%)$ perceberam a necessidade de termos algo em movimento oscilatório para produção de ondas numa corda; essa quantidade passa para dez $(62,50 \%)$ no pós-teste;

. seis alunos $(37,50 \%)$ perceberam que um ponto numa corda (ou mola) durante a passagem de uma onda executa movimento oscilatório; essa quantidade passa para dez $(62,50 \%)$ no pós-teste;

. 12 alunos (75,00\%) representaram a luz saindo de uma lâmpada com segmentos de reta; essa quantidade passa para $13(81,25 \%)$ no pós-teste, com pequenas diferenças: todas as respostas no primeiro caso não indicavam o sentido de propagação; no segundo caso, apenas em uma resposta foi indicado o sentido de propagação e, em dois casos, foram também traçadas uma ou mais linhas fechadas em volta da lâmpada;

. 12 alunos (75,00\%) que achavam haver alguma relação entre ondas e luz, com justificativas pouco consistentes; essa quantidade passa para $16(100,00 \%)$ nos pós-testes com justificativas mais consistentes.

Com esses dados temos indícios de uma evolução conceitual pois, dos conceitos iniciais apresentados sobre produção, propagação de ondas e a relação entre ondas e luz, os alunos, em geral, apresentaram conceitos mais próximos do que é cientificamente aceito, no pós-teste. Porém, percebemos que não houve evolução conceitual significativa sobre a representação da luz saindo da lâmpada, pois os alunos apresentaram, basicamente, as mesmas representações antes e depois, e acreditamos que uma representação considerada correta seria aquela com segmentos de reta orientados. Talvez isso tenha acontecido devido à ênfase ao tratamento ondulatório durante as aulas, apesar de termos utilizado, em alguns momentos, o modelo de raios.

Em algumas questões do pós-teste, queríamos avaliar o que os estudantes conseguiram reter sobre os conceitos de reflexão, interferência e difração, que foram trabalhados durante as aulas. Analisando as respostas encontramos:

. oito respostas $(50,00 \%)$ consideradas corretas sobre o fenômeno da reflexão, quatro $(25,00 \%)$ indicando apenas que a reflexão ocorre quando a onda encontra um obstáculo, e uma $(6,25 \%)$ alegando que ocorre apenas quando a onda retorna; as outras respostas não foram consideradas corretas. Temos, então, um total de 13 respostas $(81,25 \%)$ consideradas aceitáveis dentro do esperado;

. oito respostas (50,00\%) aceitáveis sobre o fenômeno da interferência, quatro $(25,00 \%)$ indicando apenas que um fenômeno ocorre quando ondas se encontram, e uma $(6,25 \%)$ fazendo 
apenas referência à interferência construtiva e destrutiva; as outras respostas não eram corretas. Temos, então, um total de 13 respostas $(81,25 \%)$ corretas ou bem próximas do esperado;

. oito estudantes $(50,00 \%)$ reconheceram que, na difração, a onda contorna um obstáculo, mas não citam que ela é parcialmente interceptada por ele; três respostas $(18,75 \%)$ parcialmente corretas quando citam apenas que a difração ocorre quando uma onda é interceptada por um obstáculo. Temos, então, um total de $68,75 \%$ de respostas muito próximas do esperado.

Esses dados sugerem que boa parte dos estudantes conseguiu reter aspectos pertinentes à reflexão, interferência e difração. Porém, não logramos êxito em fazer o aluno explicitar, na sua resposta, que a onda deve ser parcialmente interceptada por um obstáculo para que haja difração, apesar de termos dado ênfase a esse aspecto durante as aulas. Acreditamos que poderíamos ter trabalhado melhor essa ideia, comparando a diferença entre uma onda totalmente interceptada com uma parcialmente interceptada.

\section{Teste 1 - Conceitos iniciais sobre ondas}

Analisando as respostas obtidas nesse teste, acreditamos ter identificado o seguinte conceito-em-ação: a senoide como uma representação geométrica viável para uma onda transversal periódica produzida na corda. Porém, só em algumas respostas $(37,50 \%)$ a representação foi feita exatamente para uma oscilação completa.

Analisando as respostas obtidas nesse teste, acreditamos ter identificado os seguintes teoremas-em-ação:

- deve-se movimentar a extremidade de uma mola para cima e para baixo para produzirmos, nela, uma onda $(87,50 \%)$; devemos movimentá-la verticalmente $(12,50 \%)$;

- um ponto de uma mola se movimenta para cima e para baixo durante a passagem de uma onda transversal $(68,75 \%)$; movimenta-se transversalmente $(12,50 \%)$;

- as ondas que se propagam na superfície da água não são unidimensionais porque elas não se propagam apenas ao longo de uma linha (50,00\%); não são unidimensionais com justificativa inconsistente $(6,25 \%)$;

- a quantidade de oscilações que minha mão executa em 1 segundo, em movimento repetitivo e regular, para gerar uma onda transversal na mola, pode ser determinada dividindo a quantidade total de oscilações pelo tempo gasto em executá-las $(81,25 \%$ com unidade correta na resposta e $18,75 \%$ com unidade incorreta);

- o tempo gasto para minha mão executar uma oscilação completa pode ser determinado dividindo 1 pela frequência $(37,50 \%$ com unidade correta na resposta e $12,50 \%$ com unidade incorreta);

- o valor da velocidade de onda pode ser calculado dividindo a distância percorrida pelo tempo gasto em percorrê-la $(56,25 \%$ com unidade correta na resposta e $6,25 \% \mathrm{com}$ unidade incorreta);

- a equação fundamental das ondas pode ser obtida a partir da expressão que fornece o valor da velocidade de um móvel em movimento uniforme (6,25\%); apenas a equação fundamental das ondas é apresentada (37,50\%); apenas a expressão que fornece o valor da velocidade de um móvel em movimento uniforme é apresentada (6,25\%).

Cada resultado acima citado foi obtido de uma questão (ou item de uma questão) do teste 1. Notamos que mais da metade da turma de trabalho conseguiu expressar teoremas-em- 
Silva, J. A.; Sousa, C. M. S. G.

ação consistentes, ou parcialmente consistentes com relação ao que era esperado. Isso nos leva a crer que as aulas funcionaram efetivamente nos moldes das situações, tal como preconiza a teoria dos campos conceituais.

\section{Teste 2 - Reflexão}

Analisando as respostas obtidas nesse teste, acreditamos ter identificado os seguintes conceitos-em-ação:

- ao ser solicitada a representação de um raio de onda para um dado conjunto de frentes de onda retas incidentes em uma superfície plana, em todas as respostas está presente, pelo menos, um raio de onda; em $75,00 \%$ dos casos ele foi posicionado corretamente; uma resposta $(6,25 \%)$ foi considerada parcialmente correta;

- ao ser solicitada a representação das frentes de onda refletidas e o respectivo raio de onda, $56,25 \%$ dos alunos responderam, coerentemente com as leis da reflexão, as frentes e o respectivo raio; duas respostas $(12,50 \%)$ foram consideradas parcialmente corretas;

- ao ser requerida a representação de apenas um raio de onda incidente em uma superfície plana e o respectivo raio de onda refletido, com a reta normal no ponto de incidência e os ângulos de incidência e de reflexão, em $68,75 \%$ das respostas os estudantes representaram corretamente, para essa situação proposta, o ângulo de incidência, o ângulo de reflexão, o raio incidente, o raio refletido e a reta normal; quatro respostas $(25,00 \%)$ foram consideradas parcialmente corretas;

- ao ser solicitada a representação de raios de onda incidentes em superfícies esféricas cilíndricas, para frentes de onda retas, em oito respostas $(50,00 \%)$ houve representação correta; em seis respostas $(37,50 \%)$ os raios eram apresentados, mas não eram representados com a direção ou com os sentidos corretos, sendo consideradas respostas parcialmente corretas.

Julgamos ter identificado os seguintes teoremas-em-ação:

- o ângulo de incidência e o ângulo de reflexão têm medidas iguais $(75,00 \%)$ na reflexão ondulatória; esses ângulos não têm medidas iguais $(18,75 \%)$;

- frentes de ondas retas se propagando na superfície da água, ao incidirem em uma superfície côncava, convergem ao sofrerem reflexão, e divergem se a superfície for convexa (56,25\%); essas frentes de ondas convergem para essas duas superfícies (6,25\%);

- a luz apresenta comportamento ondulatório ao sofrer reflexão (56,25\%); a luz é algo que sofre reflexão $(37,50 \%)$.

Observando os conhecimentos-em-ação (conceitos e teoremas-em-ação) explicitados, constatamos que as respostas consistentes foram maioria em todas as questões analisadas, o que nos leva a crer na eficácia das situações propostas.

Observamos também, em todas as questões, respostas parcialmente consistentes, evidenciando alunos que poderiam apresentar maior evolução conceitual, se estivessem predispostos a isso e se fossem submetidos a um novo conjunto de situações pertinentes a esse conteúdo. 


\section{Teste 3 - Interferência}

Nesse teste, nosso objetivo era o de identificar teoremas-em-ação relativos às situações trabalhadas durante as aulas, sobre o fenômeno da interferência. Acreditamos ter identificado os seguinte teoremas-em-ação:

- quando pulsos de mesmo formato produzidos em uma corda se cruzam, eles sofrem interferência (50,00\%); quando pulsos de mesmo formato se cruzam eles sofrem interferência, mas, também, sofrem reflexão entre eles $(31,25 \%)$;

- quando pulsos produzidos em uma corda com mesmo formato se cruzam, ocorre interferência construtiva, se eles tiverem a mesma fase; e interferência destrutiva, se eles tiverem fases contrárias; e após a interferência, esses pulsos recuperam seus formatos iniciais $(75,00 \%)$. As respostas a seguir são aquelas consideradas parcialmente consistentes: ocorre apenas interferência destrutiva $(6,25 \%)$; ocorre apenas interferência construtiva $(6,25 \%)$; ocorrem as interferências, mas os pulsos não continuam após o cruzamento $(6,25 \%)$;

- ao ser apresentado, em um desenho, um esquema de frentes de ondas circulares produzidas regularmente na superfície de certa porção de água, para 31,25\% dos alunos outra onda circular produzida na mesma superfície, e, em fase com a primeira, possibilita a visualização do fenômeno de interferência de ondas. As respostas a seguir são aquelas consideradas parcialmente consistentes em relação ao esperado: apenas produzindo outra onda circular na mesma superfície $(43,75 \%)$; apenas produzindo outra onda $(12,50 \%)$;

- duas ondas circulares, produzidas em fase na mesma superfície de certa porção de água, produzem interferência construtiva quando há encontro de crista com crista ou vale com vale, e interferência destrutiva quando há encontro de crista com vale (43,75\%); há interferência construtiva quando há encontro de crista com crista, vale com vale e crista com vale $(50,00 \%)$;

- após o encontro, as frentes de cada onda produzidas numa certa porção de água continuam como se não houvesse ocorrido o cruzamento (68,75\%); quando as frentes de cada onda se encontram, ocorre apenas interferência $(31,25 \%)$.

Cada resultado acima listado foi obtido de um item de uma questão. Analisando esses resultados, concluímos que a quantidade de respostas consistentes e parcialmente consistentes é bem maior que as inconsistentes ou sem resposta.

Nesse teste, trabalhamos interferência construtiva e destrutiva, primeiro com pulsos unidimensionais e, em seguida, na superfície da água. Os alunos demonstraram dificuldades em transportar a ideia do fenômeno da interferência em uma dimensão para duas dimensões. Mostraram, também, dificuldades em perceber a necessidade de termos fontes produzindo ondas em fase, para visualizar o fenômeno de interferência, apesar de termos chamado a atenção para essa condição durante as aulas.

\section{Teste 4 - Difração}

Mais uma vez, nosso principal objetivo era o de identificar os teoremas-em-ação apresentados pelos alunos quando expostos a situações referentes à difração. As questões faziam referência às situações trabalhadas durantes as aulas; com isso, acreditamos ter identificado os seguinte teoremas-em-ação: 
Silva, J. A.; Sousa, C. M. S. G.

- difração é a propriedade que uma onda apresenta de contornar um obstáculo ao ser parcialmente interceptada por ele $(6,25 \%)$. As respostas a seguir são aquelas consideradas parcialmente consistentes: é a propriedade que uma onda apresenta de contornar um obstáculo (43,75\%); é a propriedade apresentada por uma onda quando ela é interceptada por um obstáculo $(18,75 \%)$;

- ondas com frentes retas produzidas na superfície da água se tornam curvas ao sofrerem difração $(56,25 \%)$; ondas com frentes retas produzidas na superfície da água se tornam curvas, porém nem sempre curvando a partir da frente que não é interceptada (37,50\%);

- para se visualizar com nitidez a difração da luz, podemos fazer um estreito feixe de laser ser interceptado por pequenos obstáculos ou atravessar pequenas fendas $(62,50 \%)$; com pequenos obstáculos ou pequenas fendas podemos visualizar o fenômeno da difração da luz (37,50\%). (Nessa última resposta, os alunos não faziam referência à incidência da luz);

- como a luz pode sofrer difração, ela apresenta comportamento ondulatório $(56,25 \%)$. As respostas a seguir são aquelas consideradas parcialmente consistentes em relação ao esperado: a luz é algo que realmente difrata (18,75\%); a difração da luz é mais difícil de ser visualizada $(12,50 \%)$;

- a difração de uma onda com frentes retas interceptadas por um obstáculo central, ou por obstáculos formando duas fendas, forma dois conjuntos de ondas separados que sofrem interferência $(31,25 \%)$. As respostas a seguir são aquelas consideradas parcialmente consistentes em relação ao esperado: a difração de uma onda com frentes retas interceptadas por um obstáculo central, ou por obstáculos formando duas fendas (sem citar a formação de dois conjuntos de ondas separadas), provoca o fenômeno de interferência (12,50\%); a difração de uma onda com frentes retas interceptadas por um obstáculo central, ou por obstáculos formando duas fendas (citando apenas um desses casos), forma dois conjuntos de ondas separados que sofrem interferência (18,75\%); a difração de uma onda com frentes retas interceptadas por um obstáculo central, ou por duas fendas (citando apenas um desses casos e sem citar os dois conjuntos de ondas formadas), provoca o fenômeno da interferência $(18,75 \%)$.

A partir desses resultados, notamos poucas respostas inconsistentes, e aquelas parcialmente consistentes estão próximas do que é cientificamente aceito. Isso nos mostra alunos que atingiram um grau satisfatório de conhecimentos pertinentes ao campo conceitual trabalhado durante as aulas e alunos que explicitaram teoremas-em-ação que podem evoluir para aqueles cientificamente aceitos.

As situações apresentadas nos testes 3 e 4 levavam os alunos a, essencialmente, elaborar proposições. Por isso, nesses testes, o nosso foco era o de identificar teoremas-em-ação ao invés de conceitos-em-ação.

\section{Confrontando o grupo de trabalho e o grupo de comparação}

Na Figura 1 apresentamos um gráfico comparativo entre as médias obtidas a partir das notas dos testes.

A partir desses dados, constatamos que o grupo de trabalho teve melhor desempenho porque, em todos os testes analisados, as médias das notas dos alunos desse grupo foram melhores. Acreditamos que esse melhor desempenho se deve ao tratamento diferenciado dado a esses alunos, que foram estimulados a explicitarem seus invariantes operatórios, nos propor- 
cionando oportunidades de intervir no processo de aquisição do conhecimento e promover uma evolução conceitual mais efetiva.

Figura 1. Gráfico comparativo entre as médias das notas dos testes

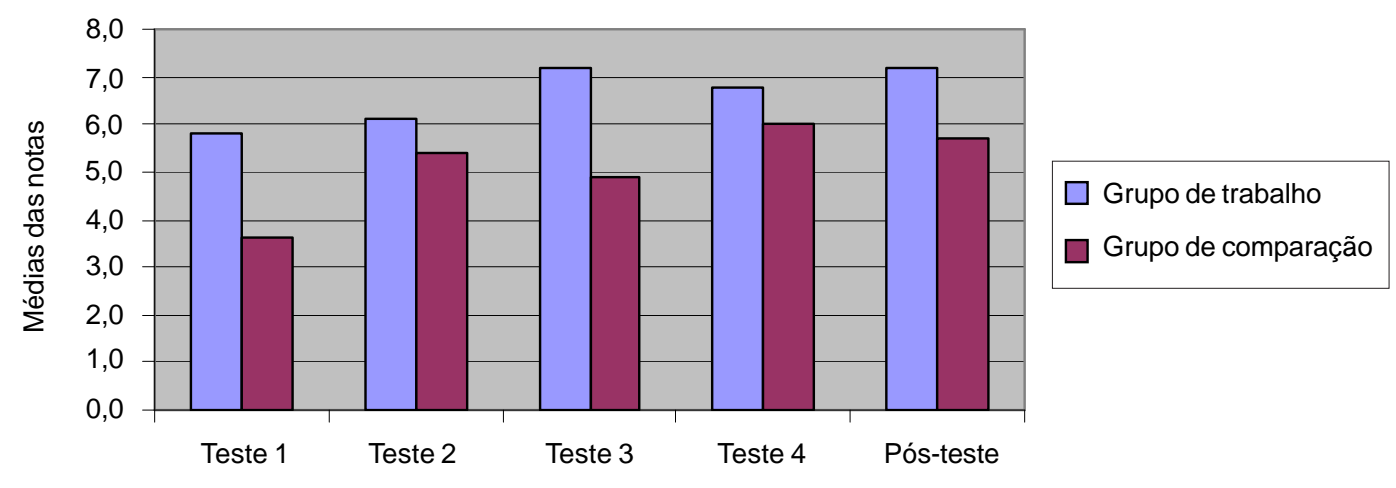

Fonte: elaborado pelos autores a partir de dados da pesquisa.

\section{As aulas gravadas em áudio}

Nas aulas do grupo de trabalho nas quais tentávamos promover evolução conceitual, por meio de situações instrucionais, nos moldes da proposta de Vergnaud (2007), era feito um trabalho de explicitação de conhecimentos-em-ação, partindo de atividades experimentais interativas e perguntas. A partir das respostas dos alunos, procurávamos aproximá-las ao máximo dos conhecimentos cientificamente aceitos. Todo esse conjunto de tarefas e metas consistia das situações propostas no nosso trabalho, por meio das quais procurávamos dar sentidos aos conceitos. A seguir, apresentamos a transcrição de alguns trechos que foram gravados em áudio, nos momentos em que dialogávamos com os alunos, após a apresentação de uma atividade experimental. As respostas transcritas não foram, necessariamente dadas pelo mesmo aluno; selecionamos aquelas que nos pareceram mais representativas.

Nas aulas sobre reflexão de feixes de luz, iniciamos com uma revisão de tudo o que foi apresentado sobre reflexão na cuba de ondas. Em seguida, apresentamos obstáculos com os mesmos formatos, mas agora espelhados, e, ao invés de ondas na água sendo interceptadas, usamos feixes de laser provenientes de uma caneta:

Professor: "O que acontecerá se eu incidir um feixe de laser no espelho plano?"

Aluno: "Vai quebrar".

Professor: "Vai quebrar?"

Aluno: "Não, vai refletir". [O professor apresenta feixes de laser refletindo em um espelho plano]. 
Silva, J. A.; Sousa, C. M. S. G.

Professor: "Vamos observar como se comporta o feixe de luz refletido; compare com um raio de onda refletido na superfície plana".

Aluno: "É igualzinho".

Professor: "O que acontecerá se eu incidir um feixe da luz laser no espelho côncavo e convexo?” [O professor apresenta feixes de luz laser refletindo em uma superfície refletora côncava e convexa, paralelos ao eixo principal].

Aluno: "Refletem iguais aos raios de onda".

Professor: "Raios de onda e raios de luz refletem obedecendo as mesmas leis; o que isso sugere?"

Aluno: "É a mesma coisa".

Outro aluno: "A luz é uma onda".

A partir dessa aula, esperávamos que os alunos começassem a perceber o comportamento ondulatório da luz, a partir da similaridade da reflexão de raios de onda e raios de luz. Tivemos a necessidade de lançar mão de elementos da Óptica Geométrica, ao representarmos graficamente o estreito feixe de laser como um raio. Nessas situações trabalhadas, vários alunos mostraram estarem convencidos do comportamento ondulatório da luz ao perceberem essa similaridade; certificamos isso pelos termos usados nas respostas acima, quando pedimos aos alunos para compararem as reflexões de raios de onda e raios de luz.

Antes de apresentarmos a difração na cuba de ondas, propusemos algumas situações nas quais frentes de onda retas eram parcialmente interceptadas por obstáculos, e questionamos sobre qual seria o formato das frentes não interceptadas. Pouquíssimos alunos sugeriram a possibilidade de essas ondas contornarem os obstáculos; para a maioria, as frentes continuam retas sem difratar. Para aqueles que sugeriram a possibilidade de alguma difração, as frentes continuariam sempre retas e só se espalhariam após certa distância do obstáculo. A partir dessa discussão, reproduzimos, na cuba de ondas, todas as situações propostas, usando como obstáculos pedaços de madeira, e projetávamos na parede usando um retroprojetor:

Professor: "Para esse caso, qual o formato das frentes não interceptadas?”

Aluno: "Ela 'curvou' o obstáculo."

Professor: "Este fenômeno se chama difração e pode ocorrer com qualquer onda".

Ao apresentar cada caso, em geral, os alunos perceberam a onda contornando o obstáculo quando parcialmente interceptada por ele; o termo "curvou o obstáculo" foi usado nesse sentido. Após apresentarmos a difração por uma fenda, promovemos a seguinte discussão:

Professor: "Compare nesse caso a onda difratada e a onda produzida quando o meu dedo toca na água; qual é a diferença?” [o professor reproduz essas situações na cuba].

Aluno: "A diferença é pequena". 
Professor: "Perceba que a fenda se comporta como uma fonte de onda com frentes circulares, e quanto menor a fenda mais acentuada é difração para a mesma onda". [O professor varia o comprimento da fenda].

Queríamos que os alunos visualizassem uma fenda se comportando como uma fonte de onda com frentes circulares. Pelas respostas dadas, entendemos que isso foi notado com facilidade.

Após apresentarmos a difração por dupla fenda:

Professor: "Observe as ondas difratadas; o que acontece?"

Aluno: "A mesma coisa só que agora com dois círculos".

Professor: "Essas ondas com frentes circulares que partem das fendas estão em fase; o que acontece com elas?"

Aluno: "Elas se misturam".

Professor: "Quando é que ocorre difração com as ondas? Use suas palavras".

Aluno: "Quando elas se dividem".

Professor: "Ocorre quando elas contornam obstáculos a serem parcialmente interceptadas por eles".

Entendemos que o termo "se misturam" foi uma alusão à interferência ocorrida com as ondas difratadas; a interferência de ondas bidimensionais circulares foi discutida em aulas anteriores. A resposta "quando elas se dividem" foi uma referência à onda difratando pela fenda; nota-se a dificuldade do aluno em descrever esse fenômeno com os termos cientificamente aceitos. Procurávamos sempre aproximar os termos usados pelos alunos, por meio de argumentos, aos termos considerados mais apropriados.

Após termos discutido essas situações, inclusive dando como exemplo a difração do som, houve a seguinte discussão:

Professor: "Tenho dito que a luz a presenta comportamento ondulatório; sendo assim, ela também não deveria difratar? O que vocês acham? Aluno: Acho que sim".

Outro aluno: "Acho que não; se fosse assim, agora estaria de dia, porque a luz do Sol que chega ao outro lado da Terra chegaria até nós". [Lembrando que no momento dessa discussão era noite].

Professor: "Vamos lembrar que a luz deve ser parcialmente interceptada".

Aluno: Acho que não, onde não há obstáculo ela passa, mas não contorna.

Outro aluno: "Se a luz tem um comportamento de onda eu acho que sim".

Professor: "é verdade que a difração da luz não é facilmente percebida no dia-a-dia".

Aluno: "Mas um pouquinho ela contorna só que a gente não percebe". 
Silva, J. A.; Sousa, C. M. S. G.

Professor: "A difração da luz é menos evidente por ela ter pequeno comprimento de onda; mas é possível percebermos esse fenômeno com a luz".

Em seguida, apresentamos pequenos obstáculos (cílios postiços, fio de náilon, dentes de um pente) ao invés dos obstáculos de madeira usados na cuba, e pequenas fendas produzidas com um corte de estilete num pedaço de papel escuro, ao invés da fendas usadas na cuba. $\mathrm{E}$, ao invés de ondas na água sendo parcialmente interceptadas, usamos feixes laser provenientes de uma caneta:

Professor: "Se fizermos um estreito feixe de luz laser ser parcialmente interceptado por estes pequenos obstáculos e passar par cialmente nestas pequenas fendas, será que conseguiremos visualizar um fenômeno de difração?" [Fizemos, então, várias demonstrações de feixes de luz laser passando por esses obstáculos, gerando várias figuras de difração projetadas na parede, na sala de aula escura].

Finalizamos as aulas tentando evidenciar que a luz também sofre interferência:

Professor: "Se podemos observar padrões de interferência quando ondas na superfície da água difratam será que podemos observar o mesmo com a luz? O que vocês acham?"

Aluno: "Não sei, se a luz é um tipo de onda acho que sim". [O professor usa mais uma vez a cuba e mostra casos nos quais podemos observar interferência, e também usa círculos concêntricos impressos em duas lâminas transparentes para retroprojetor].

Professor: "Será que podemos repetir essas situações com luz e observar um padrão de interferência? O que vocês acham?"

Aluno: "Não sei". [Pedimos para os alunos observarem com atenção a figura de difração projetada no quadro, quando o feixe de laser é interceptado pelo fio de náilon e por duas fendas bem estreitas; nesse momento, as lâmpadas da sala estavam apagadas].

Professor: "Observe essa figura de difração projetada no quadro; ela é contínua?"

Aluno: "Sim".

Professor: "Olhe mais de perto".

Aluno: "Na verdade ela é pontilhada".

Professor: "Por que ela é pontilhada?"

Aluno: "Não sei". [refizemos toda a discussão desde a cuba até a figura de difração observada na parede e queríamos que o aluno concluísse que também observávamos uma figura de interferência].

Aluno: "Se podemos comparar com a interferência na cuba, podemos dizer que nos pontos escuros há interferência destrutiva e nos pontos mais claros interferência construtiva". 
Fazer com que o aluno concluísse que, a partir do que observávamos, a luz pode sofrer interferência, não foi uma tarefa fácil. Nenhum aluno notou que a luz difratada que projetávamos era pontilhada, e isso só ocorria quando pedíamos para alguém se aproximar e observar com cuidado. Feito esse trabalho de convencimento, tínhamos de fazer com que o aluno entendesse que isso era devido ao comportamento ondulatório da luz, e resolvemos fazer isso comparando com a interferência observada na cuba. Ao final, acreditamos que muitos alunos se convenceram da possibilidade da luz difratar e sofrer interferência.

Como foi evidenciado nas discussões iniciais, pouquíssimos alunos percebiam a possibilidade de uma onda difratar, e a maioria conseguiu evoluir conceitualmente e explicitar o seguinte teorema-em-ação a partir das situações propostas: uma onda pode contornar um obstáculo. Porém poucos citavam que ela deveria ser parcialmente interceptada.

Ao tentarmos evidenciar a possibilidade de a luz difratar, observamos como o tratamento a partir da explicitação de conceitos-em-ação foi produtivo, porque os alunos, naturalmente, notaram que, se a luz apresenta comportamento ondulatório, ela deve difratar; sua difração não deve ser facilmente percebida. Além disso, um aluno achava esse fenômeno impossível porque, se fosse assim, a luz do Sol contornaria a Terra. Tudo isso nos deu grandes possibilidades de apresentar situações que evidenciassem difração e interferência da luz.

A dificuldade apresentada para se perceber a difração e interferência da luz era esperada; são fenômenos difíceis de serem identificados no cotidiano, e terminamos a sequência de aulas sentindo a necessidade de trabalhar mais situações sobre esse assunto. Além disso, tivemos algumas dificuldades extras para trabalharmos as aulas finais: encontrávamo-nos em situação de final de semestre, com alunos mais dispersos, e tínhamos, ainda, de aplicar o quarto teste e o pós-teste.

\section{Considerações finais}

Em geral, os resultados foram considerados satisfatórios porque identificamos, na maior parte dos casos, alunos que conseguiram expressar conhecimentos-em-ação condizentes ou próximos do que era esperado após a intervenção; isso foi constatado pela análise dos testes e pela comparação do pré-teste com o pós-teste. Como é previsto na teoria dos campos conceituais, a evolução conceitual nem sempre ocorre de um só golpe e, nesse caso, os estudantes deveriam ser submetidos a um novo ciclo de situações, tarefa nem sempre possível de ser executada devido ao tempo estipulado que temos para trabalhar com eles.

Acreditamos que os alunos avaliados nos testes estavam predispostos a aprender, pois, de um universo de cem alunos (36 do grupo de comparação e 64 do grupo de trabalho), apenas 26 (dez do grupo de comparação e 16 do grupo de trabalho) participaram de todas as etapas avaliativas. Segundo Ausubel, a predisposição para aprender é condição necessária para que ocorra aprendizagem significativa. Além disso, ao compararmos as notas obtidas nos testes e no pós-teste, o grupo de trabalho se saiu melhor; creditamos isso ao tratamento diferenciado dado a esse grupo, cujos estudantes foram levados a expressar seus conhecimentos-em-ação.

Para aqueles cujos testes não foram analisados, temos a seqüência de aulas gravadas em áudio e, pelos trechos transcritos, observamos que, com persistência, conseguíamos levar muitos a explicitarem raciocínios coerentes ao longo das situações propostas. 
Silva, J. A.; Sousa, C. M. S. G.

Pelos resultados obtidos, acreditamos que os estudantes absorveram bem a correspondência do comportamento de uma onda com o da luz nos fenômenos da reflexão, interferência e difração, indicando a viabilidade de se começar um curso de Óptica a partir da teoria ondulatória. Nota-se, também, a viabilidade de se começar a usar o modelo de raio a partir da teoria ondulatória, ou seja, tratarmos a Óptica Geométrica como um caso particular da Óptica Ondulatória. Ao tratarmos a reflexão de feixes de luz, tivemos que, naturalmente, usar o modelo de raios de luz e, nas aulas seguintes, usamos o modelo ondulatório para explicarmos a difração e interferência da luz.

As condições de infra-estrutura para a realização deste estudo eram, de maneira geral, precárias. Para a realização das nossas atividades, a escola oferecia quadro, giz e um retroprojetor. O restante do material, quando nós não tínhamos, foi comprado em lojas comerciais. A maioria dos alunos que participa da Educação de Jovens e Adultos do $3^{\circ}$ segmento (equivalente ao Ensino Médio do curso regular) nesta unidade de ensino tem como objetivo principal apenas obter um diploma equivalente ao Ensino Médio; reclamam quando um professor pede para comprar uma apostila, não têm hábito de leitura e poucos pensam em cursar o Ensino Superior. No início, ofereceram certa resistência para responder as perguntas durante as aulas, e reclamavam do grau de exigência das avaliações; não estavam acostumados a desenvolver os procedimentos exigidos pelo nosso estudo. Mas, com calma e persistência, conseguimos estabelecer nosso ritmo de trabalho, necessário para implementar o tratamento a contento.

A maioria dos autores de livros didáticos existentes hoje no mercado brasileiro apresenta, primeiro, a Óptica Geométrica para, mais tarde, no capítulo sobre ondas, apresentar a Óptica Ondulatória. No nosso trabalho, revertermos essa ordem e, por falta de tempo, não avaliamos o impacto na sequência de um curso de Óptica Geométrica. Portanto, deixamos as seguintes questões em aberto: será que os alunos continuariam a entender a luz como tendo comportamento ondulatório? Eles perceberiam que o modelo de raios e o modelo ondulatório são apenas construções para interpretarmos o comportamento da luz? Será que eles reconheceriam sob quais condições o modelo ondulatório, ou o modelo de raios, deve ser usado? Que novas situações deveríamos propor aos alunos para eles terem condições de evoluir conceitualmente? 
O modelo ondulatório como estratégia ...

\section{Referências}

ANDRÉS, M. M.; PESA, M. A. Conceptos-en-acción y teoremas-en-acción en un trabajo de laboratorio de Física. Revista Brasileira de Pesquisa em Educação em Ciências, Belo Horizonte, v. 4, n. 1, p. 59-75, 2004. Disponível em: <http://revistas.if.usp.br/rbpec/ article/view/143/128>. Acesso em: 18 jan. 2008.

GIRCOREANO, J. P.; PACCA, J. L. A. O ensino de óptica na perspectiva de compreender a luz e a visão. Caderno Catarinense de Ensino de Física, Florianópolis, v. 18, n. 1, p. 26-49, 2001.

GRECA, I. M.; MOREIRA, M. A. Além da detecção de modelos mentais dos estudantes. Uma proposta representacional integradora. Investigações em Ensino de Ciências, Porto Alegre, v. 7, n. 1, p. 31-53, 2002. Disponível em: <http://www.if.ufrgs.br/ienci/artigos/ Artigo_ID81/v7_n1_a2002.pdf>. Acesso em: 18 dez. 2007.

MOREIRA, M. A. Teorias de aprendizagem. São Paulo: EPU, 1999.

A teoria dos campos conceituais de Vergnaud, o ensino de ciências e a pesquisa nesta área. Investigações em Ensino de Ciências, Porto Alegre, v. 7, n. 1, p. 7-29, 2002. Disponível em: <http://www.if.ufrgs.br/ienci/artigos/Artigo_ID80/v7_n1_a2002.pdf>. Acesso em: 18 dez. 2007.

PAULO, I. J. C. de; PAULO, S. R. de; RINALDI, C. Um estudo sobre a origem e desenvolvimento de concepções alternativas sobre a natureza da luz ao longo da escolarização a nível médio e fundamental. In: ENCONTRO NACIONAL DE PESQUISA EM ENSINO DE CIÊNCIAS, 1., 1997, Águas de Lindóia. Atas... Disponível em: < http:/ /www.nutes.ufrj.br/abrapec/ienpec/ienpec.html>. Acesso em: 03 fev. 2014.

SOUSA, C. M. S. G.; FÁVERO, M. H. Análise de uma situação de resolução de problemas de física, em situação de interlocução entre um especialista e um novato, à luz da teoria dos campos conceituais de Vergnaud. Investigações em Ensino de Ciências, Porto Alegre, v. 7, n. 1, p. 55-75, 2002. Disponível em: <http://www.if.ufrgs.br/ienci/artigos/ Artigo_ID82/v7_n1_a2002.pdf>. Acesso em: 18 dez. 2007.

VERGNAUD, G. ¿En qué sentido la teoría de los campos conceptuales puede ayudarnos para facilitar aprendizaje significativo? Investigações em Ensino de Ciências, Porto Alegre, v. 12, n. 2, p. 285-302, 2007. Disponível em: < http://www.if.ufrgs.br/ienci/artigos/ Artigo_ID172/v12_n2_a2007.pdf>. Acesso em: 26 out. 2009.

Artigo recebido em 23/01/13. Aceito em 20/10/13. 